\title{
A atuação de advogados e organizações não governamentais na judicialização da saúde pública no Brasil: a quem será que se destina?
}

The acting of lawyers and non-governmental organizations in public health judicialization in Brazil: to whom is it intended?

La actuación de los abogados y las organizaciones no gubernamentales en la judicialización de la salud pública en Brasil: ¿a quién va dirigido?

Hudson Pacifico Silva ${ }^{1}$

Keyla Ketlyn Passos Pimenta ${ }^{2}$

RESUMO. Introdução: O presente estudo busca compreender a atuação de advogados e organizações não governamentais no fenômeno da judicialização da saúde no Brasil, com base em um conjunto de ações judicias julgadas em primeira e segunda instância na Comarca de Campinas no ano de 2012. Métodos: Estudo descritivo e retrospectivo, com dados coletados por meio de entrevistas com 27 advogados, responsáveis por 78 ações judiciais. Resultados: De modo geral, os advogados cobram pelos honorários profissionais, representam clientes com elevado poder aquisitivo, solicitam os benefícios da justiça gratuita para seus clientes, mantêm relações com diversas associações sem fins lucrativos que atuam na área da saúde, exploram esse nicho de mercado e possuem uma prática voltada para a litigância. Identificou-se a atuação de duas organizações não governamentais, que mantêm relações com diversos outros atores, incluindo empresas do complexo econômicoindustrial da saúde. Conclusão: Argumenta-se que a judicialização da saúde não contempla os grupos mais vulneráveis da sociedade, sendo permeada por relações duvidosas e pouco transparentes entre os atores que dela participam. Além disso, o judiciário carece de conhecimento sobre os elementos da realidade em que atua e que, agindo de forma não articulada como os outros membros do poder público, não é capaz de realmente mitigar o problema da saúde pública.

Palavras-chave: Judicialização da saúde. Sistema Único de Saúde. Poder judiciário. Advogados. Organizações não governamentais.

ABSTRACT. Introduction: This study seeks to understand the role of lawyers and nongovernmental organizations in the process of judicialization of health in Brazil, based on a set of lawsuits decided at first and second instances in the judicial district of Campinas in 2012. Methods: Descriptive and retrospective study, with data collected through interviews with 27 lawyers, responsible for 78 lawsuits. Results: In general, lawyers charge for professional fees, represent clients with high purchasing power, request the benefits of free justice for their clients, maintain relationships with several non-profit organizations working in

\footnotetext{
${ }^{1}$ Economista, Doutor em Ciências pela Universidade de São Paulo e pós-doutorado na área de inovações em saúde no Departamento de Administração de Saúde da Universidade de Montreal, Canadá. Pesquisador do Instituto de Pesquisa em Saúde Pública da Universidade de Montreal, Canadá, e professor colaborador do Departamento de Medicina Preventiva da Universidade de São Paulo - São Paulo, São Paulo. Brasil. Email: hp.silva@umontreal.ca

${ }^{2}$ Advogada, Mestra em Ciências Humanas e Sociais Aplicadas pela Universidade Estadual de Campinas. É aluna do curso de Gestão de Políticas Públicas da Faculdade de Ciências Aplicadas da Universidade Estadual de Campinas, Limeira, Brasil. E-mail: keylapassos@gmail.com
} 
health, exploit this niche market and have a dedicated practice to litigation. We identified two non-governmental organizations that maintain relations with many other actors, including private companies of the health industry. Conclusion: It is argued that the judicialization of health does not include the most vulnerable groups in society, being permeated by dubious and non-transparent relationships among stakeholders that participate of the process. Moreover, the judiciary lacks knowledge about the elements of reality in which it operates and, acting isolated from other public authorities, is not able to really mitigate the problem of public health in Brazil.

Keywords: Judicialization of health. Brazilian Unified Health System. Judiciary. Lawyers. Non-governmental organizations.

RESUMEN. Introducción: Este estudio busca entender el papel de los abogados y las organizaciones no gubernamentales en el proceso de judicialización de la salud en Brasil, basado en un conjunto de demandas decididas en primera y segunda instancias en el distrito judicial de Campinas en 2012. Metodología: Estudio descriptivo y retrospectivo, con los datos recogidos a través de entrevistas con 27 abogados, responsables de 78 demandas. Resultados: En general, los abogados cobran por honorarios profesionales, representan a clientes de alto poder adquisitivo, solicitan los beneficios de la justicia gratuita para sus clientes, mantienen relaciones con varias organizaciones sin fines de lucro que trabajan en salud, explotan este nicho de mercado y tienen una práctica dedicada a litigio. Se identificaron dos organizaciones no gubernamentales que mantienen relaciones con muchos otros actores, incluidas las empresas privadas de la industria de la salud. Conclusión: Se sostiene que la judicialización de la salud no incluye a los grupos más vulnerables de la sociedad, está impregnado de relaciones dudosas y no transparentes entre los actores que participan del proceso. Por otra parte, el poder judicial carece de conocimiento sobre los elementos de la realidad en la que opera y, actuando aisladas de otras autoridades públicas, no es capaz de mitigar realmente el problema de la salud pública en Brasil.

Palabras-Ilave: Judicialización de la salud. Sistema Único de Salud. Poder judicial. Abogados. Organizaciones no gubernamentales.

\section{Introdução}

Matéria publicada recentemente no Jornal do Brasil (1) divulgou que diversos especialistas, incluindo representantes do Governo, Poder Judiciário, Comunidade Médica e Sociedade Civil, se reuniram em evento realizado na Academia Nacional de Medicina (ANM) para debater questões relacionadas à judicialização da saúde. De acordo com a matéria, as ações judiciais contra o poder público, as operadoras de planos privados de assistência à saúde e os médicos envolvem cifras astronômicas e podem levar o setor de saúde ao colapso. A título de exemplo, menciona que somente no Estado de São Paulo o governo estadual responde a 50.700 processos judiciais, envolvendo gastos na ordem de $\mathrm{R} \$ 114$ milhões por mês no cumprimento das demandas das pessoas que recorrem à justiça. 
Dessa forma, a judicialização da saúde constitui um dos grandes desafios para a gestão das ações e serviços públicos de saúde no país.

O fenômeno da judicialização da política é de grande relevância mundial no debate das políticas públicas em razão do impacto das decisões judiciais no processo de tomada de decisão em políticas públicas $(2,3)$. No campo da saúde pública, a judicialização se refere à busca pela garantia de acesso às ações e serviços públicos de saúde por intermédio de ações judiciais. A judicialização da saúde, inserida no fenômeno maior da judicialização da política, tem manifestado impacto no campo da administração pública, principalmente quanto às questões orçamentárias e equitativas (4).

O trabalho que cunhou o termo judicialização da política, descrevendo pela primeira vez esse fenômeno, foi organizado por Tate e Vallinder (5) na coletânea The Global Expansion of Judicial Power. Publicada em 1995, a obra descreve a judicialização da política como o fenômeno de revisão das decisões de um poder político pelo poder judiciário tomando como base a constituição. Em uma descrição mais contemporânea do fenômeno, outros autores (3) definem o termo judicialização da política de forma semelhante: a busca pela resolução de conflitos por meio do judiciário em áreas cuja atuação é majoritariamente política e tomando como base a constituição do país.

No Brasil, a tentativa de resolução de conflitos políticos em saúde por meio do poder judiciário apenas se tornou relevante após a promulgação da Constituição Federal de 1988, que possibilitou a atuação do poder judiciário em matérias que eram, a priori, de competência dos poderes legislativo e executivo. Afastando-se do sistema constitucional anterior, que permitia, por meio da legislação infraconstitucional, limitar o acesso à assistência médica aos segurados da Previdência Social, a Constituição de 1988 consagrou a saúde como direito social de todos os brasileiros (art. 6º ), inseriu-a como uma das áreas que integram a seguridade social (art. 194) e estabeleceu que ela deve ser garantida pelo Estado mediante a adoção de um conjunto amplo de políticas públicas destinadas à redução do risco de doença e de outros agravos, assim como ao acesso universal às ações e serviços para sua promoção, proteção e recuperação (art. 196). Posteriormente, diversos aspectos relativos à organização e ao funcionamento do Sistema Único de Saúde (SUS) foram regulamentados por legislação infraconstitucional, com destaque para a Lei Orgânica da Saúde (6,7), o Pacto pela Saúde (8), o Decreto 7.508/2011 (9) e a Lei 12.401/2011 (10). 
Junto às precisões legais e constitucionais vieram também dilemas em sua aplicação. Isso porque, após a promulgação da Constituição Federal de 1988, pessoas passaram a ingressar com ações judiciais a fim de reivindicar os mais diversos bens e serviços em saúde em face do Estado. De acordo com Pepe et al. (11), a maior parte das demandas judiciais é proveniente de processos individuais de cidadãos reivindicando o fornecimento de medicamentos, muitos dos quais ainda não foram incorporados pela assistência farmacêutica do SUS, não contam com registro no país ou foram prescritos para indicação terapêutica não constante do registro sanitário (uso off label). Outra característica importante se refere ao fato de que a maioria dos pedidos tem sido deferida pela autoridade judicial, tendo como praticamente única base a prescrição medicamentosa apresentada pelo reivindicante.

Revisões da literatura $(12,13)$ identificaram as principais ideias dispostas nas publicações sobre o tema da judicialização em saúde no Brasil: o direito à saúde é prioritário em relação à reserva do possível ${ }^{3}$; o aumento da judicialização não está atrelado à absorção de direitos sociais pela sociedade; não é razoável a condenação do Estado ao custeio de medicamentos sem registros ou tratamentos experimentais; a judicialização pode ser fonte de interesses privados; a judicialização pode colocar em risco a continuidade de políticas públicas; a judicialização pode ser indutora da construção e melhoramento de políticas públicas; a judicialização vai contra o ideal de justiça distributiva; as ações judiciais no campo da saúde deveriam contar com uma análise mais criteriosa por parte dos magistrados; e a hipossuficiência econômica e o estado de urgência são as principais causas dos pedidos.

A literatura recente sobre o tema da judicialização da saúde no Brasil tem abordado também diversas outras questões importantes, incluindo: a interferência do judiciário em critérios de utilização de medicamentos, mais especificamente como ferramenta da indústria de farmacêutica $(11,14)$; a existência de demandas judiciais que culminam na alocação de recursos de forma incompatível aos princípios do SUS, gerando possíveis iniquidades (15); a atuação dos poderes e seus limites $(16,17)$; a incorporação inadequada de novas tecnologias no SUS (18); a judicialização como mecanismo de efetivação individual do direito à saúde pública (19) e de salvação do SUS (20).

\footnotetext{
${ }^{3}$ A reserva do possível no orçamento público se refere ao dilema econômico da escassez. A teoria da reserva do possível surgiu na Corte Constitucional alemã na década de 1970, por meio das decisões sobre o direito constitucional à educação que afirmavam que os direitos sociais de natureza prestacional, ou seja, que envolvessem custos efetivos do Estado, deveriam ficar sujeitos à reserva da lei e à disponibilidade de recursos.
} 
Apesar do interesse crescente por parte dos estudiosos sobre o tema, a atuação dos advogados e das associações sem fins lucrativos permanece um item de pesquisa pouco explorado na literatura. São raros os estudos A partir de uma análise de 200 ações judiciais oriundas da Comarca de Campinas, São Paulo, o objetivo do trabalho é descrever as motivações e as formas de participação desses atores no fenômeno da judicialização da saúde pública no Brasil.

\section{Metodologia}

Tratou-se de estudo descritivo e retrospectivo, com base em um mix de dados primários e secundários. Os dados primários, de natureza qualitativa, foram coletados por meio de entrevistas realizadas com uma amostra de advogados que atuaram em ações judiciais julgadas em primeira e segunda instâncias no ano de 2012. Essas ações judiciais, que forneceram os dados secundários necessários para a identificação dos advogados, foram selecionadas com base nos seguintes critérios: serem oriundas da Comarca de Campinas; julgadas pelo Tribunal Estadual no período correspondente ao ano de 2012; propostas em face do poder público; de caráter individual; e que reivindicam o direito fundamental à saúde.

A amostra foi constituída por 200 ações judiciais, cujos dados foram coletados por meio de consultas ao sítio do Tribunal de Justiça do Estado de São Paulo (TJSP) na internet e agrupados em quatro categorias: identificação da demanda; existência de liminares e resultados da decisão liminar; decisões do tribunal e de primeira instância; e sentenças e recursos de sentença. Os dados foram organizados em planilha Excel e depois analisados por meio de tabelas de estatística descritiva geradas a partir do software SPSS 23.

Identificou-se a atuação de 103 advogados, responsáveis por 173 ações judiciais. Desse total, foram realizadas entrevistas com 27 advogados (26\% do total), responsáveis por 78 processos (39\% do total). Os dados para contato foram obtidos por meio de vista aos próprios autos e pelo sítio da Ordem dos Advogados do Brasil na internet. As conversas ocorreram por telefone, encontros presenciais e troca de mensagens eletrônicas (e-mails). Não foi possível entrevistar todos os advogados da amostra em virtude das seguintes limitações: inexistência de dados atualizados para contato; advogados já falecidos; indisponibilidade de agenda; e recusa a participar do estudo.

As informações coletadas nas entrevistas com os advogados se referem aos seguintes itens: motivações para atuação do advogado na ação judicial (motivações filantrópicos ou 
cobrança de honorários profissionais); relação mantida entre profissional e cliente (se amigos, parentes ou desconhecidos); quantidade anual de ações dessa natureza que, em média, são iniciadas pelo advogado; existência de contato pelo cliente ou advogado com instituição específica (ONGs, associações de pacientes, etc.) sobre o tema da ação, incluindo a qualificação do contato (se está relacionado com o início da ação).

\section{Resultados}

Uma breve caracterização das ações 200 ações judiciais podem ser visualizada na tabela 1, que traz a distribuição das ações segundo diversas variáveis. Os dados permitem verificar a seguinte situação:

- $\quad$ A esfera estadual (por meio da Secretaria de Estado da Saúde e outros órgãos) aparece como réu da ação em $70,5 \%$ dos casos, ao passo que os municípios (por meio das respectivas prefeituras ou secretarias municipais de saúde) aparecem em 20,5\%. Ambas as esferas - estadual e municipal - aparecem simultaneamente como réus em 9,0\% das ações;

- As decisões judiciais proferidas pelo Tribunal de Justiça do Estado de SP (TJSP) se referem a processos que tiveram seu início em diferentes momentos: 15\% das ações foram iniciadas no mesmo ano do julgamento (2012), 17,5\% foram iniciadas no ano anterior (2011), 26\% em 2010 e 36,5\% em anos anteriores a 2010; além disso, $12 \%$ dos processos analisados haviam sido iniciados antes de 2007;

- $\quad$ A grande maioria $(80,5 \%)$ dos autores das ações (demandantes) encontra-se na faixa etária de 18 a 65 anos (adultos), 15,5\% na faixa etária de mais de 65 anos (idosos) e somente 3,0\% possuem menos de 18 anos;

- $\quad$ Considerando o tipo de petição inicial, observa-se predominância do mandado de segurança em $67,5 \%$ dos processos; ações ordinárias representaram $21,5 \%$ dos processos, obrigação de fazer 9,0\% e ação civil pública 2,0\%;

- Houve pedido de liminar em $74,5 \%$ das ações, sendo a liminar deferida em $53 \%$ delas. Além disso, o prazo para apreciação da liminar foi de até um mês a contar da data da propositura da ação na grade maioria dos casos $(66,4 \%)$; 
- $\quad$ Em 86,5\% das ações o advogado do autor é de natureza particular. Apesar disso, a justiça gratuita ${ }^{4}$, que isenta o autor de custas e emolumentos judiciais, foi utilizada na quase totalidade dos casos $(99,5 \%)$;

- $\quad$ Prevalência de enfermidades crônicas, com pacientes portadores de diabetes $(28,5 \%)$, câncer $(20,0 \%)$, degeneração miópica $(7,0 \%)$, hepatite $(5,5 \%)$ e psoríase $(3,0 \%)$

- Nas ações onde foi possível identificar o valor da causa ( $n=150), 62,7 \%$ se referem a causas com valor até $R \$ 1000,19,3 \%$ a valores situados na faixa de $R \$ 1001$ até $R \$ 5000,8,7 \%$ a valores na faixa de $R \$ 5001$ até $R \$ 10000$ e 9,3\% acima de $R \$$ 10000;

- Com relação à decisão de $1^{\mathrm{a}}$ instância, 58\% das decisões deferiram o pedido do autor, $37 \%$ indeferiram o pedido do autor e $5 \%$ deferiram parcialmente o pedido do autor; e

- $\quad$ Nos processos julgados em $2^{\mathrm{a}}$ instância, 53,5\% tiveram recurso improvido (mantida decisão de deferimento do pedido do autor), ao passo que $36,0 \%$ tiveram recurso provido (decisão de deferimento do pedido do autor, reformando decisão anterior).

Tabela 1. Caracterização das ações judiciais analisadas $(n=200)$.

\begin{tabular}{l|l|c}
\hline \multicolumn{1}{c}{ Variável } & \multicolumn{1}{c}{ Alternativa } & Resultado (\%) \\
\hline \multirow{2}{*}{ Réu da ação } & Estado & 70,5 \\
\cline { 2 - 3 } & Município & 20,5 \\
\cline { 2 - 3 } & Estado e município & 9,0 \\
\hline \multirow{2}{*}{ Ano de início da ação } & 2012 & 15,0 \\
\cline { 2 - 3 } & 2011 & 17,5 \\
\cline { 2 - 3 } & 2010 & 26,0 \\
\cline { 2 - 3 } & Antes de 2010 & 36,5 \\
\hline \multirow{2}{*}{$\begin{array}{l}\text { Faixa etária do autor } \\
\text { da ação }\end{array}$} & Menos de 18 anos & 3,0 \\
\cline { 2 - 3 } & De 18 a 65 anos & 80,5 \\
\hline
\end{tabular}

\footnotetext{
${ }^{4}$ A obtenção de justiça gratuita fica vinculada apenas à declaração de próprio punho do autor de que não pode arcar com as custas e emolumentos judiciais, declaração essa que é juntada ao processo sem necessidade de comprovação de situação financeira. Esse pedido quase nunca é impugnado.
} 
Cuadernos Iberomericanos

de Derecho Sanitario

\begin{tabular}{|c|c|c|}
\hline Variável & Alternativa & Resultado (\%) \\
\hline & Mais de 65 anos & 15,5 \\
\hline \multirow[t]{4}{*}{ Tipo de petição inicial } & Mandado de segurança & 67,5 \\
\hline & Ação ordinária & 21,5 \\
\hline & Obrigação de fazer & 9,0 \\
\hline & Ação civil pública & 2,0 \\
\hline \multirow{4}{*}{$\begin{array}{l}\text { Pedido e resultado de } \\
\text { liminar }\end{array}$} & Pedido liminar deferido & 53,0 \\
\hline & Pedido liminar indeferido & 18,5 \\
\hline & Pedido liminar parcialmente deferido & 2,5 \\
\hline & Não houve liminar ou informação não localizada & 25,5 \\
\hline \multirow{2}{*}{$\begin{array}{l}\text { Prazo de apreciação } \\
\text { da liminar }\end{array}$} & Até um mês a contar da data da propositura da ação & 66,4 \\
\hline & $\begin{array}{l}\text { Mais de um mês a contar da data da propositura } \\
\text { ação }\end{array}$ & 33,6 \\
\hline \multirow[t]{2}{*}{ Advogado do autor } & Particular & 86,5 \\
\hline & Defensor público & 13,5 \\
\hline \multirow[t]{2}{*}{ Justiça gratuita } & Sim & 99,5 \\
\hline & Não & 0,5 \\
\hline \multirow[t]{6}{*}{ Enfermidade principal } & Diabetes & 28,5 \\
\hline & Câncer & 20,0 \\
\hline & Degeneração macular & 7,0 \\
\hline & Hepatite & 5,5 \\
\hline & Psoríase & 3,0 \\
\hline & Outras & 36,0 \\
\hline \multirow{4}{*}{$\begin{array}{l}\text { Valor da causa (em } \\
\mathrm{R} \$)\end{array}$} & Até 1000 & 62,7 \\
\hline & De 1001 até 5000 & 19,3 \\
\hline & De 5001 até 10000 & 8,7 \\
\hline & Mais de 10000 & 9,3 \\
\hline \multirow{3}{*}{$\begin{array}{l}\text { Decisão de } 1^{\text {a }} \\
\text { instância }\end{array}$} & Deferido & 58,0 \\
\hline & Indeferido & 37,0 \\
\hline & Deferido parcialmente & 5,0 \\
\hline \multirow[t]{3}{*}{$\begin{array}{l}\text { Decisão de } 2^{\mathrm{a}} \\
\text { instância }\end{array}$} & $\begin{array}{l}\text { Recurso improvido (mantida decisão de deferimento } \\
\text { do pedido do autor) }\end{array}$ & 53,5 \\
\hline & $\begin{array}{l}\text { Recurso provido (decisão de deferimento do pedido } \\
\text { do autor, reformando decisão anterior) }\end{array}$ & 36,0 \\
\hline & Recurso parcialmente provido & 5,0 \\
\hline
\end{tabular}




\begin{tabular}{l|l|c}
\hline \multicolumn{1}{c}{ Variável } & \multicolumn{1}{c}{ Alternativa } & Resultado (\%) \\
\hline & $\begin{array}{l}\text { Recurso improvido (mantida decisão de deferimento } \\
\text { parcial do pedido do autor) }\end{array}$ & 2,0 \\
\cline { 2 - 3 } & $\begin{array}{l}\text { Recurso improvido (mantida decisão de } \\
\text { indeferimento do pedido do autor) }\end{array}$ & 1,0 \\
\cline { 2 - 3 } & Outros & 2,5 \\
\hline
\end{tabular}

Fonte: Tribunal de Justiça do Estado de SP. Elaboração própria

\section{Atuação dos advogados}

Em sua grande maioria (89\%), os advogados com os quais foi possível estabelecer contato e que concordaram em participar do estudo responderam que cobraram normalmente os honorários profissionais pelas ações. Houve quatro exceções: dois advogados disseram que um de seus casos se tratava de uma atuação remunerada pelo Estado por meio de participação de convênio com a Defensoria Pública, outro mencionou que um de seus casos se tratava de ação movida em nome de sua esposa e outro que moveu a ação em nome de um tio.

No que se refere à relação mantida entre profissional e cliente, os advogados responderam que, de modo geral, o cliente era um como outro qualquer, não havendo nada de especial nas relações entre eles que não houvesse na relação estabelecida com clientes de outros tipos de ações. Houve duas exceções, já contempladas também na questão anterior: profissionais que moveram ações em nome de parentes próximos - esposa e tio. Também cabe ressaltar que os advogados mencionaram que alguns clientes do tipo de ação estudada já fazem parte da clientela normal, que geralmente frequentam os mesmos espaços sociais e são pessoas comumente instruídas e de meios financeiros razoáveis. Todos os advogados foram uníssonos em dizer que não possuíam clientes em situação de pobreza $^{5}$ no que se refere às ações estudadas. Curiosamente, um dos profissionais relatou que, de seus clientes em cerca de sete processos da amostra, todos "moravam no Alphaville", condomínio de luxo bastante conhecido em Campinas. Mais curiosamente ainda, os dados das ações judiciais revelam que os autores de alguns destes casos declararam outra localidade de domicílio nos autos.

\footnotetext{
${ }^{5}$ O termo pobreza não foi abordado na acepção jurídica do termo, mas sim na acepção sociológica, ou seja, no que se relaciona às noções de escassez de recursos, desigualdade, vulnerabilidade e exclusão social. Os advogados declararam ter consciência do significado de pobreza nessa acepção.
} 
Sobre a questão da relação de cliente ou advogado com organização específica sobre o tema (organizações não governamentais, empresas, etc.) e se isso foi a causa do contato entre ambos a fim de mover a ação, a grande maioria dos advogados respondeu conhecer organizações que atuam na Comarca de Campinas, mas que elas não são a causa do contato com clientes. No entanto, três advogados relataram que é muito frequente que se mantenha contato com determinadas organizações não governamentais que indicam e encaminham clientes aos escritórios. Afirmaram também que isto é regra entre os profissionais com grande volume de ações dessa natureza. Um deles relatou que foi contratado por uma associação sem fins lucrativos para mover esse tipo de ação, sendo os custos dos processos arcados pela própria associação; disse também que alguns dos processos que iniciou como advogado dessa associação fazem parte da amostra estudada.

Já sobre o número de ações dessa natureza movidas por ano dentro e fora da comarca pelos advogados, as respostas foram variadas. Dois terços dos profissionais disseram que essas causas apareciam muito raramente, sendo que o processo constante da amostra era, muitas vezes, o único movido naquele ano. De forma geral esses dois terços disseram mover de um a dois processos do tipo ao ano. Já a outra parte declarou ingressar com uma grande quantidade desses processos todos os anos, seis deles em especial disseram mover entre 15 e 40 ações dessa natureza por ano, enquanto outro profissional disse chegar a 240 ações em um único ano. Vale ressaltar que ficou bem esclarecido aos advogados que a pergunta se tratava apenas de ações movidas contra o Estado (latu sensu) em todo território nacional.

Sobre a posição dos advogados com relação ao tema, todos declararam acreditar que a litigância é o único meio eficaz para reivindicar o direito do cliente. Afirmaram que não há possibilidade de conciliação ou mediação com os representantes do poder público e nem é possível lançar mão de instrumentos administrativos para discussão do problema em razão da ausência ou ineficácia desses meios. Também afirmaram categoricamente que a administração pública é falha na gestão dos recursos (fizeram várias menções à corrupção e à procrastinação), bem como que os recursos disponíveis, se bem geridos, seriam suficientes para fazer valer a garantia constitucional à saúde. Os profissionais explicitam com orgulho a importância das suas atuações. 


\section{As organizações não governamentais}

Foi possível identificar duas organizações principais que atuam no tema de forma a servir de ponte entre advogado e cliente em parte das ações da amostra. São elas a Associação de Assistência a Portadores de Hepatites e Transplantados Hepáticos do Estado de São Paulo (ONG Saúde em Vida) e a Associação dos Familiares, Amigos e Portadores de Doenças Graves (AFAG). Outras informações, colhidas nos endereços eletrônicos dessas instituições e outros sítios da internet, indicam que pode existir uma relação entre elas e as empresas farmacêuticas, sugerindo uma possível influência dessas organizações na escolha dos médicos pelos pacientes e, consequentemente, no tratamento adotado.

A ONG Saúde em Vida foi fundada em 2003 e idealizada para orientar e conscientizar a população sobre as particularidades das hepatites virais. O trabalho da ONG sobre essa enfermidade engloba a divulgação de informação sobre seus efeitos, a sua propagação, os meios e formas de contaminação, as manifestações, os riscos, os métodos de detecção, tratamentos disponíveis, as maneiras de prevenção, as instituições e os profissionais especializados no tratamento da patologia e as possibilidades de recuperação. Com duas unidades na região, uma em Campinas e outra em Limeira, a ONG Saúde em Vida foi fundada por portadores de hepatites e transplantados hepáticos. A ONG declara que promove o intercâmbio de informações com outras entidades para a realização de programas e projetos de interesse social, procurando realizar parcerias com profissionais da área (infectologista, hematologista ou gastroenterologista) a fim de melhorar a saúde e a qualidade de vida dos pacientes.

Em setembro de 2009, a ONG Saúde em vida inaugurou, em Campinas, a Casa da Hepatite, que realiza exames gratuitos, visando o diagnóstico da doença e o atendimento da população em geral. No local também é oferecido gratuitamente atendimento médico e psicológico, exames laboratoriais, biopsias hepáticas e serviços de enfermagem. Também há notícias que fazem referência ao fato de que na Casa da Hepatite houve a implantação do Centro de Aplicação do Interferon 6 (medicamento usado para o combate de doenças virais, como a hepatite $\mathrm{C}$ ), além de realizadas palestras sobre hepatites e reuniões com

\footnotetext{
${ }^{6}$ De acordo com a ANVISA, o Interferon costuma ser indicado para portadores do genótipo 1 da Hepatite Viral que nunca foram tratados e para aqueles que não tiveram sucesso com o tratamento disponível até o momento. Esse novo medicamento deve ser administrado em associação com outros dois medicamentos que já são utilizados no tratamento da Hepatite C, o Boceprevir e a Ribavirina, para que alcance o resultado esperado. Note-se o elevado índice de judicialização do Boceprevir e da Ribavirina nos processos estudados (pag 50 deste trabalho), lembrando-se que o Boceprevir fo incorporado pelo Ministério da Saúde apenas em julho de 2012.
} 
familiares e portadores da doença para a melhoria do convívio social e familiar e para o esclarecimento da população.

De março a outubro de 2009 a ONG Saúde em Vida realizou 27 campanhas educativas e abertas à população, algumas promovidas em lugares públicos e outras em empresas privadas nas cidades da região de Campinas (Piracicaba, Paulínia, Rio Claro, Araras, Limeira, Vinhedo, etc), nas quais foram realizados 5.795 testes de detecção da doença. A ONG também estabeleceu parcerias com o Centro de Oncologia de Campinas a fim de promover campanhas sobre as formas de câncer relacionadas à hepatite. O Centro de Oncologia de Campinas, também conhecida como COC, é uma clínica privada que atende pacientes por meio de pagamento direto e por meio de convênios médicos. A clínica declara abertamente que a parceria com laboratórios é seu ponto forte, sendo que "novos medicamentos lançados no exterior são recebidos quase que imediatamente, garantindo ao paciente medicação de ponta"7.

A ONG Saúde em Vida foi apontada pelos advogados como atora no processo de judicialização no Comarca de Campinas na medida em que informa os pacientes sobre a via judicial, indica advogados e até têm sua própria assessoria jurídica para esse fim específico. Como demonstrado, outras informações também indicam que existe uma relação estreita entre a ONG e algumas organizações privadas lucrativas, sugerindo a influência direta de empresas farmacêuticas na sua atuação e orientação dos pacientes, bem como uma possível influencia dessas organizações na escolha dos médicos e no tratamento adotado.

Já a AFAG, Associação dos Familiares, Amigos e Portadores de Doenças Graves, é uma entidade de abrangência nacional, sediada em Campinas e que, desde 2005, declara atuar na defesa dos direitos das pessoas acometidas por doenças raras e graves. A instituição tem como fim levar informação à população sobre doenças graves e raras, promover eventos de conscientização, apoiar outras associações com fins correlatos e ajudar na estruturação de unidades públicas de atendimento, visando com isso diminuir as diferenças e promover a dignidade da pessoa humana ${ }^{8}$. A AFAG mantém relação com dezenas de outras organizações sediadas no Brasil, em países da América Latina e na Europa. Ela foi apresentada pelos advogados como uma das organizações que informa a população sobre o recurso judicial.

\footnotetext{
${ }^{7}$ http://www.oncologia.com.br/clinica.php, acesso em 11 de novembro de 2015.
}

8 http://www.afagbrasil.org.br/afag/, acesso em 11 de novembro de 2015. 
Em consulta ao sítio eletrônico da associação pode-se constatar que a última cartilha lançada teve como título "Saúde ao alcance de todos: faça valer seus direitos" 9 . Elaborada por uma advogada e dirigida aos pacientes, a cartilha tem informações práticas sobre direitos, modelo de requerimento para acesso a dados médicos, sobre a obrigação de fornecimento de tratamentos, exames médicos e insumos pelo SUS, sobre saúde suplementar e planos de saúde, informações sobre isenções e abatimentos tributários, com modelos de pedido de isenção e dedução, e ainda sobre tarifas de transporte público, liberação de abonos salariais, aposentadorias por invalidez, renda mensal vitalícia (benefício de prestação continuada), previdência privada, andamento prioritário de processos judiciais, além de referência completa à legislação que toca todos os assuntos. A cartilha foi elaborada pela advogada Maria Cecília Mazzariol Volpe, que é portadora de câncer no intestino desde 2001. Ela milita em favor da divulgação dos direitos assegurados pela Constituição aos doentes de câncer e outras doenças e mantém relações com várias entidades privadas. A advogada também lançou cartilhas semelhantes junto a várias outras organizações. Por exemplo, uma versão da mesma cartilha lançada pela AFAG também foi lançada junto à clínica ONCOCAMP, clínica particular para tratamento oncológico em Campinas, que faz uso de recursos técnico-científicos atualizados. Outra versão da cartilha também foi lançada em parceria com o Instituto Brasileiro de Controle do Câncer (IBCC), como o título "Câncer: Faça valer seus direitos"10, sendo declarado na própria cartilha, pelo IBCC, que o objetivo da publicação é mostrar aos clientes que, além de oferecer profissionais altamente especializados e qualificados no tratamento dos mais diversos tipos de câncer, querem também levar ao conhecimento público informações importantes, como os direitos.

Em entrevista da Advogada dada à Folha de São Paulo em 28 de fevereiro de $2002^{11}$ ela afirma que "é muito importante que as pessoas briguem por aquilo a que têm direito. Não cura, mas colabora muito com o êxito do tratamento". Ela relata que todos devem ter consciência do direito de ter seu tratamento custeado integralmente pelo Estado e que não se pode esquecer que todos pagam impostos para que isso aconteça. Também declara que autoriza a cópia integral da cartilha aos interessados em distribuir o conteúdo e espera obter o apoio de laboratórios e hospitais.

\footnotetext{
9 http://www.afagbrasil.org.br/wp-content/uploads/2014/03/Cartilha.pdf, acesso em 11 de novembro de 2015.

${ }^{10} \mathrm{http}: / /$ www.ibcc.org.br/upload/cartilha/cartilha.pdf, acesso em 11/11/2015.

11 http://www1.folha.uol.com.br/fsp/equilibrio/eq2802200219.htm, acesso em 22/11/2015.
} 


\section{Discussão}

Pode-se fazer várias considerações acerca das informações obtidas. A primeira é que fica bastante claro que os advogados têm consciência de que as ações judiciais não são movidas pelos grupos mais vulneráveis da sociedade, ou seja, de que representam indivíduos pertencentes aos setores mais favorecidos nesse tipo de ação. Uma segunda consideração é que existe um grupo de advogados que atua mais fortemente nesse tipo de ação, o que sugere a existência de um nicho de mercado crescente, que conta com a atuação especializada de alguns advogados em ações judiciais dessa natureza.

Uma terceira consideração a ser feita é que as entrevistas realizadas com os advogados põem em causa os aspectos éticos da atuação desses profissionais, na medida em que há pedido dos benefícios da justiça gratuita em todas as ações da amostra, assim como declaração de uma situação financeira que, na maioria das vezes, não é condizente com a real condição do cliente (autor da ação). Também é possível que parte desses advogados tenha utilizado o conceito jurídico de pobreza, que reconhece o fato de que 0 cliente não tem condições de suportar o pagamento das despesas processuais sem prejuízo do sustento próprio e da família, mesmo na posse de eventuais bens. De todo o modo, é pouco provável que seja este o caso para a totalidade das ações analisadas, já que a obtenção de justiça gratuita fica vinculada apenas à declaração de próprio punho do autor de que não pode arcar com as custas e emolumentos judiciais, declaração essa que é juntada ao processo sem necessidade de comprovação de situação financeira.

Outro aspecto que chama a atenção na atuação dos advogados é que esses profissionais parecem ter uma forte formação voltada para litigância, ou seja, para a resolução de conflitos por meio do processo judicial, ficando evidente a indisposição para adotar qualquer medida alternativa ou predisposição à conciliação e mediação. Esse tipo de comportamento, porém, parece estar na contramão de uma tendência mundial em direção a uma cultura eficaz de solução extrajudicial, de modo a privilegiar a negociação realizada entre as partes antes que o conflito se torne um litígio.

Os resultados evidenciaram também a existência de relações entre os advogados e diversos tipos de organizações, incluindo empresas da indústria farmacêutica, clínicas, médicos e associações sem fins lucrativos. Destaque-se que as clínicas e as empresas farmacêuticas podem desenvolver mecanismos para estimular a orientação dos advogados para a litigância, bem como a divulgação de informações que lhes é mais favorável por meio, 
inclusive, das próprias associações sem fins lucrativos. Cabe lembrar que essas relações podem estar envolvidas em um processo bastante lucrativo para o setor privado.

É fato que o mercado de medicamentos e demais produtos e serviços de saúde apresenta grande vulto econômico e o Estado, em função das dimensões do Sistema Único de Saúde (SUS), costuma ser um cliente bastante visado pelas empresas. A Tabela 2, que sintetiza dados fornecidos pela Secretaria de Estado da Saúde de São Paulo, mostra a existência de um mercado que movimenta, por mês, em razão da judicialização, $R \$ 42,7$ milhões na compra de medicamentos, materiais, nutrição/dietas e outros itens adquiridos diretamente do setor privado e com poucas possibilidades de negociação, dado que a compra tende a ser feita de forma fragmentada e pressionada pelo tempo. Do total desse gasto estadual, $R \$ 21,8$ milhões (cerca de 50\%) se referem a produtos com vinculação de marca, ou seja, cuja decisão judicial determinou a marca específica do produto. Isso significa que a decisão vincula a administração pública à compra do produto da marca ordenada, sob pena de descumprimento da decisão.

Tabela 2. Comparativo de valores gastos $(R \$)$ para atendimentos de demandas judiciais. Itens com vinculação de marca e sem vinculação de marca. Valor estimado mensal.

\begin{tabular}{lrrr}
\hline \multicolumn{1}{c}{ Categoria } & \multicolumn{1}{c}{ Marca } & \multicolumn{1}{c}{ Sem marca } & \multicolumn{1}{c}{ Total } \\
\hline Medicamentos & $2.846 .324,16$ & $2.436 .618,83$ & $5.282 .942,99$ \\
Materiais & $17.342 .938,95$ & $17.175 .311,05$ & $34.518 .250,00$ \\
Nutrição / dietas & $1.276 .869,37$ & $1.001 .860,82$ & $2.278 .730,19$ \\
Outros itens & $321.058,85$ & $321.058,85$ & $642.117,70$ \\
Total & $21.787 .191,33$ & $20.934 .849,54$ & $42.722 .040,87$ \\
Fonte: Sistema de gerenciamento e controle de demandas judiciais (S-CODES). Secretaria de Saúde do &
\end{tabular}

Considerados os possíveis mecanismos articulados pela indústria junto às relações entre clínicas, médicos, advogados e as associações sem fins lucrativos, bem como considerando a orientação dos advogados para o litígio judicial, fica a questão se não se estaria diante da chama "indústria das liminares". A "indústria das liminares" é o nome dado ao movimento pelo qual o judiciário é usado por empresas privadas como meio para melhor vender seus produtos. Tal indústria não é movimento novo no Brasil e costuma operar por meio da parceria entre médicos, clínicas, hospitais e fornecedores. 
Várias notícias têm exposto esse possível problema em todo o Brasil. Por exemplo, o jornal Folha de São Paulo noticiou, em 20 de maio de 2015, que diversas associações têm se dedicado a aumentar a quantidade de remédios oferecidos gratuitamente no SUS, muitas delas com apoio da indústria farmacêutica, por meio da realização de encontros e promoção de eventos na tentativa de influenciar políticos, formadores de opinião, médicos e técnicos do governo (21). O Centro Brasileiro de Estudos em Saúde (CEBES) publicou, em 23 de outubro de 2015, artigo do farmacêutico da Fundação Oswaldo Cruz (Fiocruz), Leandro Farias, no qual ele afirma que o judiciário vem assumindo, por meio da judicialização da saúde, uma função para a qual não é capacitado e lança a hipótese da existência de uma máfia no setor da saúde que manipula o judiciário (22). Outra notícia veiculada pela Rede Globo, no dia 4 de janeiro de 2015, denunciou a existência da "máfia das próteses e órteses" no fenômeno da judicialização pública e privada, descrevendo que médicos chegam a ganhar cerca de cem mil reais por mês em esquemas que desviam dinheiro do SUS e encarecem planos de saúde (23).

Destaque-se que a Comissão Parlamentar de Inquérito (CPI) da Câmara dos Deputados que investiga o caso da Máfia das Órteses e Próteses aprovou, no dia 15 de julho de 2015, por unanimidade, o relatório final emitido pelo relator deputado André Fufuca (24). No documento, o relator propõe a tramitação de quatro projetos de lei para coibir as fraudes no mercado de implantes médicos, que foram comprovadas. Os projetos trazem sugestões para modernizar a regulamentação do setor de implantes, barrar práticas comerciais abusivas, tipificar o crime de corrução privada e dar transparência à relação entre médicos e empresários.

É importante destacar que algumas iniciativas envolvendo o Poder Judiciário têm sido tomadas no período recente em função da quantidade de ações judiciais na área da saúde e da necessidade de conferir maior precisão e rapidez na apreciação dessas ações. A título de exemplo, cabe mencionar as recomendações do Conselho Nacional de Justiça (CNJ) aos Tribunais para adoção de medidas com a finalidade de melhor subsidiar os magistrados e demais operadores do direito na solução das demandas judiciais envolvendo a assistência à saúde (25), a instituição do Fórum Nacional do Judiciário para monitoramento e resolução das demandas de assistência à saúde (26) e a implantação de varas especializadas nos Tribunais para processar e julgar ações que tenham por objeto o direito à saúde (27). A aprovação da Lei 12.401/2011 (10), que dispõe sobre a assistência terapêutica e a 
incorporação de tecnologia em saúde no âmbito do SUS, também representa uma tentativa de regulamentar aspectos importantes associados ao fenômeno da judicialização, na medida em que ela define que os protocolos clínicos e as diretrizes terapêuticas devem estabelecer os medicamentos ou produtos necessários nas diferentes fases evolutivas da doença ou do agravo à saúde de que tratam e que, na ausência destes, a dispensação deve ser realizada com base nas relações de medicamentos instituídas pelo gestor federal do SUS e, de forma suplementar, nas relações de medicamentos instituídas pelos gestores do SUS nos Estados e Municípios. Também é importante mencionar que a referida lei determina que os medicamentos ou produtos de interesse para a saúde devem ser avaliados quanto à sua eficácia, segurança, efetividade e custo-efetividade para as diferentes fases evolutivas da doença ou do agravo à saúde. Outra iniciativa que merece ser destacada é a parceria entre o CNJ e a Comissão Nacional para Incorporação de Tecnologias no SUS (Conitec), que disponibilizou um canal direto para responder a questionamentos dos magistrados sobre a incorporação de medicamentos, produtos ou procedimentos no SUS, além de fichas técnicas com informações simples e claras sobre medicamentos e produtos para a saúde mais demandados, incluindo a disponibilidade no SUS, a avaliação feita pela Conitec, o custo de tratamento, a existência de alternativas no sistema público de saúde e a disponibilidade de protocolos clínicos e diretrizes terapêuticas para a situação clínica relacionada.

\section{Conclusão}

A judicialização da saúde é parte integrante de um fenômeno mais amplo, a judicialização da política, que se refere à busca pela resolução de conflitos por meio do judiciário em áreas cuja atuação é majoritariamente política, tomando por base a constituição. Como a constituição brasileira estabelece que a saúde é direito de todos e dever do Estado e que, além disso, o atendimento integral é uma das diretrizes de organização do SUS, os magistrados tendem a deferir as demandas individuais relacionadas às ações e serviços de saúde, na medida em que o direito à saúde é visto como prioritário em relação à disponibilidade de recursos.

Este estudo, por meio da diversidade da natureza dos elementos considerados e analisados, sugere a existência de uma realidade geralmente ignorada ao nível dos "autos processuais" nos tribunais. Enquanto muitas instituições vinculadas ao Poder Judiciário e ao Ministério da Saúde divulgam uma série de recomendações quanto à complexidade do tema 
no que tange à judicialização da saúde pública, o judiciário acaba por ignorar muitas discussões, que nem sempre chegam aos autos.

Em uma realidade local em que o fenômeno da judicialização da saúde pública não contempla os extratos mais baixos da sociedade e é permeado por relações duvidosas e pouco transparentes entre seus atores, os magistrados e demais operadores do direito ainda se mantem exógenos à realidade fática, que vai muito além de aspectos eminentemente jurídicos. Esta afirmação não busca deslegitimar ou desqualificar a interferência judicial no tema, mas mostrar que o judiciário carece de conhecimento sobre os elementos da realidade em que atua e que, agindo de forma não articulada como os outros membros do poder público, não é capaz de realmente mitigar o problema da saúde pública.

\section{Referências}

1. Jornal do Brasil. Aumento de processos judiciais pode levar setor de saúde ao colapso. Jornal do Brasil. 28 jul 2016 [Acesso em 15 ago 2016]. Disponível em: http://www.jb.com.br/ciencia-e-tecnologia/noticias/2016/07/28/aumento-de-processosjudiciais-pode-levar-setor-de-saude-ao-colapso/

2. Yepes RU. A judicialização da política na Colômbia: casos, potencialidades e riscos. Sur, Rev. Int. Direitos Humanos, 2007, 4(6): 52-69.

3. Engelmann F, Cunha Filho MC. Ações judiciais, conteúdos políticos: uma proposta de análise para o caso brasileiro. Rev. Sociol. Polit., 2013, 21(45): 57-72.

4. Chieffi AL, Barata RB. Judicialização da política pública de assistência farmacêutica e eqüidade. Cad. Saúde Pública, 2009, 25(8): 1839-1849.

5. Tate N, Vallinder T. The global expansion of Judicial Power: The Judicialization of Politics. Nova York; Londres: New York University Press; 1995.

6. Brasil. Lei no 8.080, de 19 de setembro de 1990. Dispõe sobre as condições para a promoção, proteção e recuperação da saúde, a organização e o funcionamento dos serviços correspondentes e dá outras providências. Diário Oficial da União. Brasília [Acesso em 18 ago 2016]. Disponível em:

http://www.planalto.gov.br/ccivil_03/leis/L8080.htm

7. Brasil. Lei n 8.142, de 28 de dezembro de 1990. Dispõe sobre a participação da comunidade na gestão do Sistema Único de Saúde (SUS\} e sobre as transferências intergovernamentais de recursos financeiros na área da saúde e dá outras providências. 
Diário Oficial da União. Brasília [Acesso em 18 ago 2016]. Disponível em: http://www.planalto.gov.br/ccivil_03/leis/L8142.htm

8. Brasil. Ministério da Saúde. Portaria no 399, de 22 de fevereiro de 2006. Divulga o Pacto pela Saúde 2006 - Consolidação do SUS e aprova as Diretrizes Operacionais do Referido Pacto. Brasília, 1ำ set 2006. [Acesso em 18 ago 2016]. Disponível em:

http://bvsms.saude.gov.br/bvs/publicacoes/prtGM399_20060222.pdf

9. Brasil. Decreto oㅜ 7.508, de 28 de junho de 2011. Regulamenta a Lei oㅡ 8.080, de 19 de setembro de 1990, para dispor sobre a organização do Sistema Único de Saúde - SUS, o planejamento da saúde, a assistência à saúde e a articulação interfederativa, e dá outras providências. Diário Oficial da União. Brasília [Acesso em 18 ago 2016]. Disponível em: http://www.planalto.gov.br/ccivil_03/_ato2011-2014/2011/decreto/D7508.htm.

10. Brasil. Lei no 12.401, de 28 de abril de 2011. Altera a Lei no 8.080, de 19 de setembro de 1990, para dispor sobre a assistência terapêutica e a incorporação de tecnologia em saúde no âmbito do Sistema Único de Saúde - SUS. Diário Oficial da União. Brasília [Acesso em 18 ago 2016]. Disponível em: http://www.planalto.gov.br/ccivil_03/_Ato20112014/2011/Lei/L12401.htm.

11. Pepe VLE, Figueiredo TA, Simas L, Osorio-de-Castro CGS, Ventura M. A judicialização da saúde e os novos desafios da gestão da assistência farmacêutica. Ciênc. saúde coletiva, 2010, 15(5): 2405-2414.

12. Brito RJS. A judicialização do direito à saúde: uma revisão bibliográfica da produção científica nacional. [Monografia]. Brasília: Bacharelado em Ciências Sociais, Universidade de Brasília; 2011.

13. Oliveira MRM, Delduque MC, Sousa MF, Mendonça AVM. Judicialização da saúde: para onde caminham as produções científicas? Saúde Debate, 2015, 39(105): 525-535.

14. Marques SB, Dallari SG. Garantia do direito social à assistência farmacêutica no Estado de São Paulo. Rev. Saúde Pública, 2007, 41(1): 101-107.

15. Vieira FS. Ações judiciais e direito à saúde: reflexão sobre a observância aos princípios do SUS. Rev. Saúde Pública, 2008, 42(2): 365-369.

16. Pinheiro IA, Vieira LJM, Motta PCD. Mandando Montesquieu às favas: o caso do não cumprimento dos preceitos constitucionais de independência dos três poderes da república. Rev. Adm. Pública, 2011, 45(6): 1733-1759.

17. Baptista TWF, Machado CV, Lima LD. Responsabilidade do Estado e direito à saúde no Brasil: um balanço da atuação dos Poderes. Ciênc. saúde coletiva, 2009, 14(3): 829839.

18. Franco MGRM, Franco TB. Judicialização da Saúde: incorporação das novas tecnologias em saúde no SUS por meio de decisões judiciais. Diversitates, 2013, 5(2): 179- 
198.

19. Rosa LC. A judicialização como mecanismo de efetivação individual do direito à saúde pública. [Dissertação]. São Paulo: Programa de Estudos Pós-Graduados em Direito, Pontifícia Universidade Católica de São Paulo; 2015.

20. Fleury S. A judicialização pode salvar o SUS. Saúde Debate, 2012, 36(93): 159-162.

21. Alves G. Com apoio de farmacêuticas, associações pedem mais remédios na lista do SUS. Folha de S. Paulo. 20 mai 2015 [Acesso em 8 jan 2016]. Disponível em: http://www1.folha.uol.com.br/equilibrioesaude/2015/05/1631178-com-apoio-defarmaceuticas-associacoes-pedem-mais-remedios-na-lista-do-sus.shtml

22. Farias L. A judicialização da saúde e suas aberrações. Cebes. 23 out 2015 [Acesso em 8 jan 2016]. Disponível em: http://cebes.org.br/2015/10/a-judicializacao-da-saude-e-suasaberracoes/

23. Globo. Máfia das próteses coloca vidas em risco com cirurgias desnecessárias. Fantástico. 4 jan 2015 [Acesso em 8 jan 2016]. Disponível em:

http://g1.globo.com/fantastico/noticia/2015/01/mafia-das-proteses-coloca-vidas-em-riscocom-cirurgias-desnecessarias.html

24. Fufuca A. Comissão Parlamentar de Inquérito para investigar a cartelização na fixação de preços e distribuição de órteses e próteses, inclusive, com a criação de artificial direcionamento da demanda e captura dos serviços médicos por interesses privados Máfia das órteses e próteses no Brasil. [Relatório final de CPI]. Brasília: Câmara dos Deputados; 2015. Disponível em:

http://www.camara.gov.br/proposicoesWeb/fichadetramitacao?idProposicao=1579578

25. Brasil. Conselho Nacional de Justiça. Recomendação n 31, de 30 de março de 2010. Recomenda aos tribunais a adoção de medidas visando melhor subsidiar os magistrados e demais operadores do direito, para assegurar maior eficiência na solução das demandas judiciais envolvendo a assistência à saúde. Brasília, 31 mar 2010. Disponível em: http://www.cnj.jus.br/files/atos_administrativos/recomendao-n31-30-03-2010-presidncia.pdf.

26. Brasil. Conselho Nacional de Justiça. Resolução CNJ nำ 107, de 06 de abril de 2010. Institui o Fórum Nacional do Judiciário para monitoramento e resolução das demandas de assistência à saúde. Brasília, 7 abr 2010. Disponível em:

http://www.cnj.jus.br/files/atos_administrativos/resoluo-n107-06-04-2010-presidncia.pdf

27. Brasil. Conselho Nacional de Justiça. Resolução no 43, de 20 de agosto de 2013. Recomenda aos Tribunais de Justiça e aos Tribunais Regionais Federais que promovam a especialização de Varas para processar e julgar ações que tenham por objeto o direito à saúde pública e para priorizar o julgamento dos processos relativos à saúde suplementar. Brasília, 21 ago 2013. Disponível em: http://www.cnj.jus.br/files/atos_administrativos/recomendao-n43-20-08-2013-presidncia.pdf 
Cadernos Ibero-Americanos

de Direito Sanitário

Cuadernos Iberomericanos

de Derecho Sanitario

Recebido em: 30.ago.2016

Aprovado em: 20.dez.2016

\section{Como citar este artigo:}

Silva HP, Pimenta KKP. A atuação de advogados e organizações não governamentais na judicialização da saúde pública no Brasil: a quem será que se destina? Revista Cadernos Ibero-Americanos de Direito Sanitário. 2017 jan./mar, 6(1):9-29. 